\title{
ARTE COMO TRABALHO CRIADOR: a produção de significados de pessoas com deficiência intelectual
}

\author{
Tania Regina Rossetto \\ Nerli Nonato Ribeiro Mori
}

Resumo

O tema deste estudo é a arte na educação de pessoas com deficiência intelectual. O objetivo é discorrer sobre a constituição do ser social por meio da arte como trabalho criador; evidenciar a produção artística de pessoas com deficiência intelectual e a constituição de novos conceitos por meio da arte. A pesquisa apresenta delineamento bibliográfico e de abordagem prática, amparada no Materialismo Histórico Dialético, na Teoria Histórico-Cultural e na Teoria Histórico-Crítica. Os resultados extrapolam conceitos científicos e ganham força nas narrativas dos participantes em diversas realidades possíveis. Conclui-se que a arte como trabalho criador na educação de pessoas com deficiência intelectual apresenta-se como meio da própria existência do ser humano no mundo.

Palavras-chave: trabalho; arte; educação.

\section{ART AS CREATIVE WORK: the production of meanings the people with intellectual disabilities}

\begin{abstract}
The subject of this study is art in the education of people with intellectual disabilities. The intent is to write about the social being constitution through art as creative work; to highlight the artistic production of people with intellectual disabilities and the creation of new concepts through art. The research presents bibliographic design and practical approach, supported by Dialectical and Historical Materialism, Culturalhistorical Theory and Historical Criticism. The results extrapolate scientific concepts and gain strength from the participants' narratives in various possible realities. It is concluded that art as creative work in the education of people with intellectual disabilities presents itself as a means of human existence in the world. Keywords: work; art; education.
\end{abstract}

\section{ARTE COMO TRABAJO CREADOR: la producción de significados de personas con discapacidad intelectual}

Resumen

El tema de este estudio es el arte en la educación de personas con discapacidad intelectual. El objetivo es discutir la constitución del ser social a través del arte como trabajo creativo; evidencia la producción artística de personas con discapacidad intelectual y la constitución de nuevos conceptos a través del arte. La investigación presenta un diseño bibliográfico y un enfoque práctico, apoyado por el Material Histórico Dialéctico, la Teoría Histórico-Cultural y la Teoría Histórico-Crítica. Los resultados extrapolan conceptos científicos y ganan fuerza en las narrativas de los participantes en varias realidades posibles. Se concluye que el arte como un trabajo creativo en la educación de personas con discapacidad intelectual se presenta como un medio de existencia humana en el mundo.

Palabras clave: trabajo; art; educación. 


\section{INTRODUÇÃO}

Inicialmente faz-se necessário considerar que os escritos apresentados consistem em uma síntese de discussões realizadas em uma tese de doutoramento vinculada à área da educação de uma instituição de ensino superior estadual, desenvolvida entre o período de 2014 a 2018. Além disso, é conveniente destacar que as motivações que levaram à escolha do tema desta pesquisa lançam raízes em experiências pessoais que evidenciaram a necessidade de aprofundamento em relação aos desafios enfrentados pela educação, em específico no âmbito do ensino de arte voltado a pessoas com deficiência intelectual. Uma dessas experiências ocorreu em um dos Núcleos Regionais de Educação do Estado do Paraná, em uma reunião pedagógica com aproximadamente 50 professores da educação especial. O objetivo do encontro foi discorrer sobre a superação da arte como cópia e reprodução de modelos. No encontro, duas questões destacadas por professores participantes indicaram inicialmente a necessidade do estudo: 1) Nossos alunos não conseguem desenhar e pintar de maneira tão perfeita; 2) Já consideram nossos alunos loucos e desajustados, imagine se eles pintassem o sol de azule a maçã de alaranjado? Ambas as inquietações demonstram práticas naturalizadas no ensino de arte, as quais se potencializam na educação de pessoas com deficiência intelectual - por vezes tratadas como loucas e desajustadas. Pode-se observar que, por um lado, os professores se preocuparam com o grau de perfeição da arte; por outro, com a transgressão. Parece evidente, pela fala deles, a busca por uma via de acesso; uma vez que não é possível a total perfeição, também não se aceita a total transgressão. $O$ fato expõe a necessidade de acesso a conhecimentos que possibilitem conceber a arte como representação e não como objeto em si. Voltando à fala dos professores, seria possível então pensar em um ensino de arte no qual a composição das formas e das cores permitem que o sol seja azul e a maçã, alaranjada, sem que isto possa configurar loucura ou desajuste?

A questão permite refletir sobre a complexidade do ensino de arte na educação de pessoas com deficiência intelectual, a qual se debruça esta pesquisa. Muitos artistas foram considerados loucos e desajustados, mas nesse processo instauraram novas formas de conceber a arte e a própria existência, entre eles o holandês Vincent Van Gogh $(1853$ - 1890) e, mais recentemente, o brasileiro Arthur Bispo do Rosário (1909/1911 - 1989). No decorrer do processo histórico e social, a humanidade foi organizando novas formas de conceber a loucura que, em sua origem, está relacionada aos flagelos da Inquisição e aos expurgos do pecado, conforme escreve Foucault (2017). O autor traça o percurso da história da loucura desde que as instituições dedicadas ao tratamento da lepra passam a abrigar novas formas de inclusão/exclusão, o que se deve à origem do sistema capitalista. Na Idade Média a loucura era considerada como possessão demoníaca; na Renascença como transcendência imaginária; na constituição do sistema capitalista condena-se a ociosidade e a falta de produtividade no trabalho - lugar em que facilmente se encaixam os pobres, os doentes, as crianças, os velhos, as mulheres, as pessoas com deficiência. A produção da loucura como algo arraigado ao cerne do sistema capitalista será dificilmente admitida pela sociedade. Em vez disso, o que ocorre é a condenação do sujeito pela sua própria incapacidade de incluir-se nos padrões vigentes.

No intuito de amenizar a segregação imposta pelo sistema, observam-se diversos movimentos, entre eles, as mudanças de nomenclatura. $\mathrm{O}$ termo deficiência intelectual segue essa lógica. Muitos dos que eram chamados de loucos, de débeis e/ou doentes mentais, são categorizados na atualidade como pessoas com deficiência intelectual. $\mathrm{O}$ termo foi cunhado em 1995, no simpósio Deficiência Intelectual: Programas Politicos e Planejamento para o Futuro, estruturado pela Organização das Nações Unidas (ONU) em Nova York. Em Montreal (Canadá, 2014), na Conferência Internacional sobre Deficiência Intelectual, a Organização Panamericana de Saúde (OPAS) e a Organização Mundial da Saúde (OMS) aprovam o documento Declaração de Montreal sobre a Deficiência 
Intelectual, demarcando o termo, recomendado para encaminhar ações respectivas à área (SHIMAZAKI, MORI, 2012). Nesse cenário, evidenciam-se desafios enfrentados na educação de pessoas com deficiência intelectual, que extrapolam a mudança de nomenclatura e estendem-se ao complexo processo de inclusão/exclusão conforme o sistema econômico vigente.

Nesse entendimento, ações aparentemente inclusivas podem trazer em seu bojo uma exclusão ainda maior, em específico, no ensino de arte. Entretanto, cogita-se que o quadro pode ser revisto quando a arte é considerada como área de conhecimento e como trabalho criador, como algo que sustenta ações efetivas sobre a realidade. Ao se promover o conhecimento em arte o intuito não é que todos sejam artistas, mas que todos, caso o queiram, possam desenvolver potencialidades estéticas (MARX, ENGELS, 1986). Entretanto, esse conhecimento encontra-se arraigado à concepção de arte restrita aos que têm, supostamente, habilidades inatas (SCHLICHTA, 2009). Ao limitar-se a arte aos que têm dom e talento, colabora-se com a elitização desse conhecimento, mantendo-o reservado a algumas pessoas.

Mediante o exposto, a problemática que sustenta esta discussão consiste em demonstrar como se constitui a produção de significados na educação de pessoas com deficiência intelectual cogitando a autoprodução humana e a superação de si mesmas. Nesse percurso, objetiva-se: discorrer sobre a constituição do ser social, considerando a superação do trabalho alienado pelo trabalho criador; abordar a arte como uma das formas de apropriação da realidade, como fonte de humanização; discorrer sobre a educação na perspectiva inclusão/exclusão - conforme apontamentos teóricos; evidenciar a produção artística de pessoas com deficiência intelectual; e analisar a produção de significados - conforme a prática destacada.

Diante disso, a metodologia indica delineamento bibliográfico e de abordagem prática amparados no Materialismo Histórico Dialético, na Teoria Histórico-Cultural e na Teoria Histórico-Crítica. Por conseguinte, este estudo fundamenta-se no que é historicamente possível, diante das limitações impostas pelas determinações complexas do sistema econômico em vigor. As ponderações realizadas por meio da educação de pessoas com deficiência intelectual desempenham ação mediadora, a análise dos resultados firma-se na superação do conhecimento imediato pelo conhecimento mediato, o que implica considerar a arte como instrumento indispensável na constituição humana. Assim sendo, a discussão reverbera de maneira ampla e não se restringe apenas às pessoas com deficiência intelectual, mas a todos que, de uma forma ou de outra, são considerados improdutivos perante o modo de produção vigente.

\section{TRABALHO, ARTE E EDUCAÇÃO}

É importante reter que a abordagem realizada inter-relaciona o trabalho, a arte e a educação, buscando manter suas especificidades. O trabalho é abordado de forma ontológica, conforme apontamentos de Lukács (2013), nos quais o trabalho é categoria fundante do ser social. A arte é considerada uma das categorias do trabalho, como uma das formas de apropriação da realidade e constante produção do mundo humano, algo que rompe o cotidiano, o imediato e o utilitário. A educação é destacada como um meio privilegiado de apropriação do conhecimento produzido socialmente, um paradoxo entre inclusão e exclusão.

Conforme estudos de Lukács (2013), a transição entre a constituição natural e social ocorre pelo trabalho, que apresenta caráter mediador entre o ser humano e a natureza, o que permite a criação da própria humanidade. Para o filósofo, o trabalho contém a dualidade entre o pensado e o real, presente em todo o mundo humano, distinguindo a constituição social pela reflexão sobre a realidade, pela consciência, o que se diferencia do biologicamente determinado. Logo, o ponto predominante na determinação dos atos humanos é o desenvolvimento social objetivo, na esfera 
da ideia previamente concebida, na qual as finalidades determinam a objetivação. O trabalho impele o ser para o exterior, no sentido de transformar e dominar o material do objeto natural em objeto humanizado. Consonante a Lukács (2013), Lessa (2012) explica que esse propósito obtém êxito pela objetividade - forças externas, coletivas, sociais - em conjunto com a subjetividade - forças internas, individuais, psíquicas - que exerce um papel produtivo auxiliar. Nesse intercurso, Kosík (1976) salienta que as coisas ganham sentido mediante a criação humana, em outras palavras, o sentido não é dado, é necessário criá-lo. O que é possível pelo trabalho.

Mas no processo de desenvolvimento humano, o trabalho, segundo o sistema capitalista, deixa de ser criador da própria humanidade e instaura necessidades imediatas, oculta a consciência pela fragmentação do processo de produção, o que origina o trabalho alienado. Para Lessa (2012), a alienação é um obstáculo posto à plena explicitação da generalidade humana, corresponde às desigualdades sociais que compõem o solo fértil dos fenômenos sociais. As desigualdades ocorrem devido ao fato de que a essência da vida humana não é dada a priori nem ao acaso, mas, incorporase ao processo histórico de afastamento das barreiras naturais. Do mesmo modo, Saviani (1985) propugna que o trabalho alienado torna a existência desprezível, desfigurada, desumana, passiva, por firmar-se apenas nas aparências dos fatos e das ações cotidianas efetuadas sem reflexões. Essa condição leva o ser humano a viver em um mundo prático, utilitário, desumano e desumanizante, falta-lhe o acesso aos meios de formação e autocriação de si mesmo.

Em contrapartida, o trabalho criador, segundo Vigotski (2009), é uma das vias de acesso para a obtenção da consciência humana, permite a passagem do imediato ao mediato pela percepção e impulso do meio que precisa ser organizado com esse propósito. Em síntese, todo trabalho é criador, modifica forçosamente a natureza de quem trabalha, produz algo novo pelas mediações entre as pessoas e a natureza. Nesse processo, a imaginação humana combina, muda e cria coisas novas, mesmo que em pequenos atos. Para Vigotski (2009), essa capacidade de combinar o que já existe em novas formas é a base de toda a criação.

Nessa perspectiva, a arte é apresentada como uma das formas de apropriação da realidade e constante produção do mundo humano. Conforme estudos de Vigotski (1999), o processo de criação artística supõe elevada atividade da consciência, uma íntima relação entre o subjetivo e o objetivo, o que eleva o trabalho ao nível criador. Consonante a Vigotski (2009; 1999), Kosík (1976) defende que a arte representa o princípio criador do trabalho humano, um posicionamen to diante do mundo e das coisas, o que permite superar o mundo dos fenômenos em sua transparência e expressar forças essenciais do ser humano. Em concordância, Vásquez (2010) apresenta a arte como instrumento de luta pela sobrevivência diante de uma natureza desconhecida. Pela percepção humana a forma artística se desprende da forma utilitária e manifesta o ser.

Para Canclini (1980) a arte é produção, apropriação e transformação da realidade material e cultural e, por seu caráter criador, não se limita aos condicionamentos do modo de produção. Mas, pelo contrário, a arte elabora novos significados, percepções e concepções, tornando-se “[...] agente de transformação, um foco de criatividade e iniciativa social" (CANCLINI, 1980, p. 33). Logo, é preocupante observar o conhecimento artístico reduzido a um pequeno número de pessoas talentosas e a práticas fragmentadas e desprovidas de significados: cópia de modelos, desenho livre, técnica, passatempo. Concebida como trabalho criador, a arte materializa sentimento, emoção, memória, algo forjado, corporizado no objeto concreto, algo real com introjeção na realidade. Segundo Schlichta (2009), os objetos criados são percebidos de forma consciente ao receberem existência concreta, a materialização de experiências humanas nos objetos permite combinações significativas ao ser social, o que representa o ser e estar no mundo.

A articulação entre o natural e o social, que configura o subjetivo e o objetivo, vincula-se ao esforço de estabelecer um mundo humano em meio a um universo indiferente. Como alega Schlichta (2009), a arte cria uma realidade possível por meio da realidade objetiva. O que não é 
possível no mundo real é possível no objeto artístico, algo representativo da relação entre as pessoas em diferentes contextos históricos e sociais. O que garante o vínculo social presente no objeto de arte são elementos que estão além de circunstâncias históricas e representam algo humano, e fixam, além dos aspectos objetivos, a subjetividade. Nesse aspecto, Kosík (1976) adverte que na sociedade de modo de produção capitalista ocorre uma cisão desses aspectos — objetivo e subjetivo perfazem momentos distintos, um contra o outro: "[...] como mera subjetividade, de um lado, e como subjetividade reificada, do outro" (KOSÍK, 1976, p. 118). Entretanto, a realidade social cria circunstâncias mais ricas que a condição dada, inclui outras realidades, pelas quais forças objetivas e subjetivas produzem significado, no que pulsa o trabalho criador.

Frente a essas discussões, a educação é considerada como fator indispensável na ação sobre a realidade imediata. No intuito de tornar-se humano é imprescindível que o ser singular tenha acesso às riquezas material e espiritual, necessárias à construção como gênero humano. $\mathrm{O}$ que ocorre é que esse conhecimento se restringe a poucos e, menos ainda, às pessoas com deficiência.

A discussão sobre a educação de pessoas com deficiência é bem recente no Brasil e não difere do cenário mundial. A Lei de Diretrizes e Bases (LDB) n. 9.394 de 1996 (BRASIL, 1996) incorpora o princípio da inclusão como pedra de toque para a educação especial no país. A partir disso, ocorrem diversas mudanças que apontam para questões relevantes sobre o tema. Evans (1995) avulta as considerações do psicólogo russo Lev S. Vigotski (1896 - 1934) quando ele afirma que toda pessoa é educável, o que dá à educação um lugar de destaque. Outro aspecto a ser considerado é o das autoridades educacionais, que estão deixando de categorizar as pessoas segundo suas deficiências, conforme pode ser observado no Education Act., documento elaborado na Inglaterra em 1981. O documento considera todos os estudantes num continuum de aprendizado, todos podem ser educados de acordo com suas peculiaridades e com apoio escolar adequado.

Nesse processo, destacam-se ações que incidem sobre o movimento de inclusão, entre elas: a Declaração Universal dos Direitos Humanos adotada pela ONU (1948); a promulgação pela ONU no Ano Internacional das Pessoas Deficientes em 1981; a pressão da sociedade sobre o Estado e a organização de um documento proposto na elaboração da Constituição Federal de 1988 (BRASIL, 1988), o que garante no texto constitucional, no Artigo 205 o dever do Estado e da família; no Artigo 206 o direito de igualdade de condições para o acesso e permanência na escola estendendo-se, no Artigo 208, inciso III, o atendimento educacional especializado.

A Constituição de 1988 rompe o modelo assistencialista em prática até então, mas é a partir da década de 1990 que a discussão sobre a inclusão social ganha ênfase pelas vias da educação. O marco reside nos tratados de Jomtien e Salamanca pelos quais o Brasil se compromete com as metas internacionais de erradicação do analfabetismo e universalização do ensino. A Conferência Mundial de Educação para Todos, Jomtien, Tailândia, 1990, revigora a discussão sobre a educação de pessoas com deficiência. Em 1993, as normas das Nações Unidas conjecturam a igualdade de oportunidades como responsabilidade do Estado, devendo integrá-la no sistema educativo. Em 1994, o delineamento da inclusão de pessoas com deficiência desencadeia discussões mais acirradas sobre a inclusão e a participação social. Conforme a Declaração de Salamanca a inclusão e a participação "[...] são essenciais à dignidade humana e ao gozo do exercício dos direitos humanos. No campo da educação, tal se reflete no desenvolvimento de estratégias que procuram proporcionar uma equalização genuína de oportunidades" (ORGANIZAÇÃ̃O DAS NAÇÕES UNIDAS PARA A EDUCAÇÃO, CIÊNCIA E CULTURA - UNESCO, 1994, p. 61).

O documento reafirma o compromisso de educação para todos, a dignidade e o gozo dos direitos humanos como objetivos da educação. Nesse curso, a Declaração de Salamanca fomentou discussões sobre a educação especial no Brasil, porém, apesar do "[...] amplo debate e instituição de leis para garantir a inclusão escolar não conseguiram, ainda, alterar significativamente a situação das minorias atípicas no país" (CARVALHO, MARTINS, 2012, p. 29). Mediante a proposta de 
universalização da educação, as discussões relativas à inclusão e à exclusão são inevitáveis, pois a alienação de grupos com características heterogêneas não deixa de ocorrer. Há uma hierarquia que opera na regulação e produção das desigualdades, oprimindo pessoas com distinções físicas, intelectuais, sociais, linguísticas que estruturam o modelo de educação escolar.

A exclusão manifesta-se de diversas formas e apresenta características que envolvem segregação e integração pelo modelo de educação escolar, pressupondo preferências que naturalizam a falta de aprendizagem. Em vista disso, em 2008, instaura-se a Política Nacional de Educação Especial na Perspectiva da Educação Inclusiva (BRASIL, 2008), cuja concepção se fundamenta nos direitos humanos, alinhada a lutas e conquistas sociais; propugna a defesa de todos os estudantes estarem juntos, sem discriminação. Nesse contexto, a igualdade e a diferença são imanentes, a educação inclusiva avança na superação da lógica da exclusão. A organização educacional passa a ser repensada, formulando-se novas concepções estruturais e culturais de maneira que todos os estudantes possam ser atendidos segundo suas peculiaridades.

Integrado a essa perspectiva, instaura-se no Brasil o Estatuto da Pessoa com Deficiência, Lei n. 13.146 (BRASIL, 2015), que no Art. $1^{\circ}$ propõe: “[...] assegurar e promover, em condições de igualdade, o exercício dos direitos e das liberdades fundamentais por pessoa com deficiência, visando a sua inclusão social e cidadania”. A normatização dos direitos das pessoas com deficiência representa um avanço histórico, mas como escrevem Klein, Silva e Mata (2012), preconizar direitos sem confrontar a real forma de constituição social promotora de exclusão é apenas um modo de culpabilizar os sujeitos sem que haja mudança de fato.

É notório que várias ações intencionam a inclusão, mas as respostas vinculam-se ao cerne do modo de produção vigente, forjado no livre comércio e livre exploração do trabalho humano. Não há condições de igualdade diante dos privilégios de alguns que relegam os direitos de outros. À revelia dessa condição, mascaram-se os fatos que realmente geram desigualdades e propõem ações inclusivas no âmbito educacional, no intuito de remediar o irremediável. Por meio de indicativos de Mészáros (2007) é evidente que o processo de inclusão deixa à mostra seu lado perverso; paradoxalmente, defende-se a inclusão, mas vive-se em um sistema econômico ferozmente competitivo e excludente, considerando a produção de excedente e a acumulação de riquezas por alguns em decorrência da miséria de outros.

Em síntese, a precarização da vida humana se aprofunda pelo trabalho alienado e pela falta de acesso ao conhecimento de cunho humanizante, respectivo ao trabalho criador. A arte, estruturada nessa perspectiva, desdobra-se para além das limitações impostas e firma-se na criação de formas significativas imbuídas do acesso ao conhecimento produzido pela humanidade.

\section{APONTAMENTOS METODOLÓGICOS}

A metodologia utilizada nesse estudo considera orientações de Mori (2011), que apontam o trabalho de pesquisa como atividade básica da ciência, no sentido de reflexão sobre a realidade. Conforme já explicitado, indica-se delineamento bibliográfico e de abordagem prática, amparados no Materialismo Histórico Dialético, na Teoria Histórico-Cultural e na Teoria Histórico-Crítica. Portanto, a pesquisa, ao apresentar um caráter dialético, demonstra que a realidade não se esgota em respostas definitivas, mas pode ser superada, constituindo-se segundo o intricado dinamismo histórico. Em resumo, o procedimento metodológico parte da aparência, do imediato, passa pelas mediações abstratas e retorna ao concreto, à complexidade do real possível pela abstração do pensamento, o mediato. Segundo Martins (2006), a prática social é a referência na produção do conhecimento, caracterizada pelo princípio da unidade e pela luta dos contrários, o que corresponde à objetividade subjetivada e à subjetividade objetivada, perfazendo a realidade 
histórica e social. Os fenômenos são percebidos de imediato, como projeção primária na consciência. A essência, pelo contrário, revela-se pelas mediações e contradições que the são fundamentais. O subjetivo e o objetivo são incorporados por superação, sendo opostos indissociáveis: "[...] o que determina saber o objetivo como subjetivo, o externo como interno, o individual como social, o qualitativo como quantitativo" (MARTINS, 2006, p. 9).

Desse modo, o estudo foi realizado mediante a participação de pessoas integradas a um Projeto de Extensão de uma Universidade Estadual. O projeto atende pessoas com deficiência intelectual, de idades diferenciadas, oriundas de diversos contextos: alguns matriculados no ensino regular, outros na Associação de Pais e Amigos dos Excepcionais (APAE), outros não frequentam instituições escolares. Nas ações foram selecionadas três pessoas que manifestaram interesse de participar da pesquisa, organizada em nove encontros, com a duração de $3 \mathrm{~h}$ semanais para cada um deles. No registro dos dados, os integrantes da pesquisa tiveram seus nomes alterados como forma de preservar sua identidade, sendo especificados por duas consoantes: PY, MR, JL. Os sujeitos da pesquisa têm acima de 18 anos, PY e MR são do sexo feminino e frequentam a APAE e JL é do sexo masculino e não frequenta outros ambientes escolares. O conjunto de ações realizadas perpassou todo o processo, sendo similar em cada um dos nove encontros. Nesse percurso, realizaram-se os seguintes procedimentos, conforme Tabela 1.

Tabela 1. Procedimentos metodológicos delineados no decorrer do processo

\begin{tabular}{|c|c|}
\hline $\begin{array}{l}\text { Registro dos } \\
\text { dados }\end{array}$ & $\begin{array}{l}\text { Anotações em diário de campo, filmagem, gravação, fotografia. O posicionamento do } \\
\text { pesquisador direciona o que é anotado e ou descartado. Os dizeres dos participantes, } \\
\text { quando transcritos na íntegra foram destacados no texto por meio da escrita em itálico. }\end{array}$ \\
\hline $\begin{array}{l}\text { Critério de } \\
\text { escolha da } \\
\text { imagem }\end{array}$ & $\begin{array}{l}\text { O interesse foi captar o dissonante, o irregular, as deformações e as inquietações } \\
\text { presentes no movimento apresentado, o que rompe a ideia de arte como cópia da } \\
\text { realidade. A imagem problematiza ações cotidianas dos sujeitos, o que objetiva o olhar } \\
\text { além da aparência imediata. }\end{array}$ \\
\hline $\begin{array}{l}\text { Apresentação } \\
\text { da imagem }\end{array}$ & $\begin{array}{l}\text { A apresentação foi realizada por meio de imagens projetadas com aparelho multimídia, } \\
\text { livros, folhetos e catálogos, explanação teórica e discussão junto aos participantes. }\end{array}$ \\
\hline $\begin{array}{l}\text { Leitura de } \\
\text { imagem }\end{array}$ & $\begin{array}{l}\text { Como caracteriza Schlichta (2009) a leitura de imagens constitui representações } \\
\text { respectivas ao humano e ao social; solicita-se a ação criadora, que envolve o } \\
\text { conhecimento teórico e a criação de novas formas pela referência objetiva da imagem } \\
\text { em conjunto com a subjetividade. }\end{array}$ \\
\hline $\begin{array}{l}\text { Materiais e } \\
\text { instrumentos }\end{array}$ & $\begin{array}{l}\text { Tinta acrílica; cola branca; água; corante líquido; pincéis; pote plástico; lápis; borracha; } \\
\text { fita adesiva; suportes: papel sulfite; vidro; cartolina; imagem de obras de arte; celular } \\
\text { com utilização do recurso fotográfico; caderno; projetor multimídia; notebook. }\end{array}$ \\
\hline Técnicas & Desenho, pintura acrílica, monotipia, técnica mista. \\
\hline $\begin{array}{l}\text { Produção } \\
\text { artística }\end{array}$ & $\begin{array}{l}\text { A produção artística considera o significado dos objetos, permite o pensamento } \\
\text { abstrato por meio de escolhas conscientes. Vigotski (2007) destaca um movimento no } \\
\text { campo do significado, subordinando objetos e ações reais. Esse movimento ocorre no } \\
\text { campo abstrato, mas é situacional e concreto: "Em outras palavras, surge no campo do } \\
\text { significado, mas a ação dentro dele ocorre assim como na realidade" (VIGOTSKI, } \\
2007 \text {, p. 120). }\end{array}$ \\
\hline $\begin{array}{l}\text { Produção de } \\
\text { significados e } \\
\text { análise da } \\
\text { produção }\end{array}$ & $\begin{array}{l}\text { A produção de significados é entendida como questões subjetivas e objetivas em } \\
\text { relação constante entre o eu, o outro e o meio na formação de novas realidades. Na } \\
\text { análise da produção de significados, consideram-se as categorias: imediato, mediação, } \\
\text { mediato. A representação do imediato corresponde ao saber inicial e a representação } \\
\text { do mediato ao conhecimento elaborado. O imediato corresponde aos aspectos } \\
\text { descritivos e naturalizados da imagem; mediato é o que está oculto, são os significados } \\
\text { atribuídos para além da aparência da imagem; e mediação são todos os momentos que } \\
\text { permitem a passagem do imediato ao mediato. Na perspectiva ontológica de Lukács }\end{array}$ \\
\hline
\end{tabular}




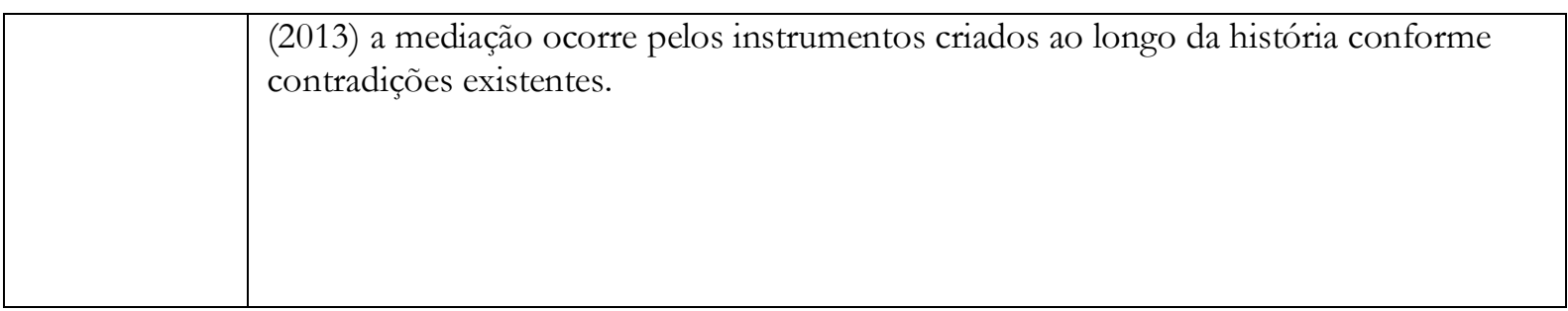

Fonte: Arquivo das autoras, 2018.

Ao longo dos encontros, considerou-se a fala como pensamento elaborado, um amálgama adjacente ao trabalho de criação artística. Desse modo, os encontros foram organizados em tópicos, articulados entre si: 1) apresentação da obra e do movimento artístico; 2) leitura de imagem; 3) análise da imagem; 4) produção artística; 5) análise da produção artística. As análises procedem segundo as categorias: imediato, mediação, mediato e seus desdobramentos. Como forma de exemplificar o processo, descreve-se apenas um dos encontros realizados, especificamente o sétimo encontro, que aborda o movimento Expressionista por meio da obra O grito (1895) do artista Edvard Munch. A escolha desse encontro em específico ocorreu de maneira aleatória, considerando que os demais encontros apresentaram a mesma estrutura, modificando-se apenas a imagem e o movimento abordado.

\section{PRODUÇÃO ARTÍSTICA DE PESSOAS COM DEFICIÊNCIA INTELECTUAL - SÉTIMO ENCONTRO}

Apresentação da obra e do movimento artístico

Apresentação da imagem da obra de Edvard Munch O grito.

Figura 1: Edvard Munch. O grito. 1895. Óleo sobre cartão $(91$ x 73,5 cm)

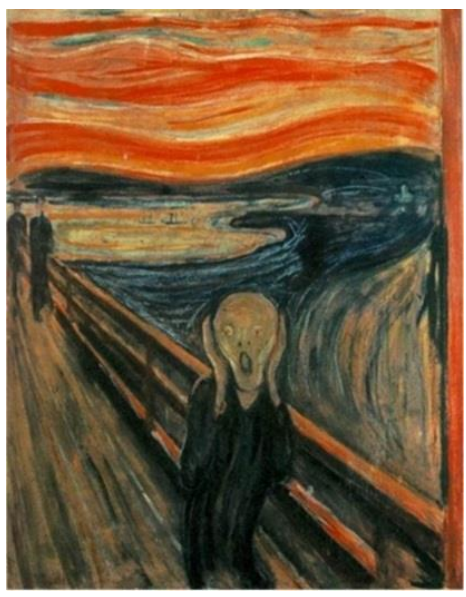

Fonte: Galeria Nacional, Oslo, Noruega. 
O Grito é uma das obras de Edvard Munch (1863-1944), pintor norueguês vinculado ao Expressionismo, corrente artística concentrada especialmente na Alemanha entre 1905 e 1930 . Os artistas expressionistas valorizavam a subjetividade e preconizavam a arte como elemento legítimo para a expressão dos sentimentos. Read (1980) explicita que o caráter geral do Expressionismo reúne artistas que atuam individualmente por toda a sociedade, convergentes no enfrentamento de um mundo hostil à originalidade. Os pintores expressionistas: “[...] alimentavam sentimentos tão fortes a respeito do sofrimento humano, da pobreza, violência e paixão, que eram propensos a pensar que a insistência na harmonia e beleza em arte nascera exatamente de uma recusa de ser sincero" (GOMBRICH, 2012, p. 565-566). Há um distanciamento da beleza, a aparência é alterada denotando algo profundo e doloroso que atormenta a alma. O grito transmite angústia, medo, solidão pela força expressiva das linhas, redução das formas e o valor simbólico da cor; emoções humanas, visíveis na expressividade da figura representada. As formas distorcidas e a expressão do personagem revelam a dor e as dificuldades que a vida pode apresentar, um grito como forma de expressão desse sentimento; é como se todo o cenário representado na composição da obra gritasse em conjunto com a face encovada e os olhos arregalados pelo medo de perder a razão.

\section{Leitura da imagem}

Com a apresentação da imagem da obra $O$ grito, os sujeitos da pesquisa interagiram com entusiasmo, contaram histórias, fizeram comentários, identificaram-se com a imagem demonstrando as próprias emoções, destacaram fatos da realidade e realizaram diversas observações que foram do real ao imaginário. Assim, foi-se encaminhando a leitura da imagem, chamando a atenção para alguns elementos de maneira que as narrativas avançassem da visão imediata para interpretações mediatas.

\section{Análise da leitura da imagem}

As impressões imediatas à imagem da obra $O$ grito percorrem elementos descritivos e visíveis na própria imagem: as formas, as cores, os elementos que a constituem. $\mathrm{Na}$ sequência, vão avançando para o mediato: o medo como uma reação humana encarnada na figura. Ocorre a percepção de cores diferentes, não naturais, uma mistura entre o real e o imaginário, o objetivo e o subjetivo. Buscam-se elementos que podem animar o fatídico destino da figura. Segundo Rodari (1982, p. 114): "É esse mecanismo - sempre presente em quem lê, ou vê um filme, ou assiste TV - que permite introduzir 'mensagens' na história, com certeza de que chegarão ao destinatário". O mesmo ocorre na leitura de imagens. O medo funesto da morte, o grito que se reverte em esperança, apenas quem avança ao nível mediato pode dizer.

Narrativa de PY: Parece uma cidade, tem dois homens passando na rua. Parece que está com a mão colocando no ouvido, as duas mãos no ouvido. Levou um susto. É uma pessoa magra, com medo, parece que perden o cabelo, foi o mar que levou o cabelo. O sol está pintado com cores diferentes. Parece que tem uma onda em cima da cabeça, espalhada e pintada com tinta e pincel, espalhada com pincel. Os dois parecem um policial e querem prender a figura. No fundo parece um prédio, um apartamento, uma casa. Parece o formato de um beijo.

Narrativa de MR: Tá na praia, no Rio de Janeiro e tem areia e mar, Copacabana. Tem pessoas andando e o sol está colorido, amarelo, branco, verde claro e laranja. O homem está assustado, com a mão na orelha, está com medo. Quando a gente está com medo, a gente se esconde. Tem branco no finalzinho do mar, é o mar de Copacabana. Rio de Janeiro, areia, mar, Copacabana pode representar diversão, férias, alegria. Também pode representar violência urbana, algo cotidiano anunciado pelos repórteres televisivos, integrando o imaginário popular repleto de fatos contraditórios. MR 
busca uma experiência coletiva. Entretanto, o sol colorido é outro elemento de contradição. Um homem assustado, com medo, com a mão na orelha, configura o outro do quadro. MR se projeta na imagem dando-lhe formas conotativas ao trazer o exemplo dos que se escondem quando têm medo. Observa-se um percurso de entrada e de saída da imagem, uma busca em entendê-la, fazê-la mais próxima.

Narrativa de JL: A figura está com medo. Eu acho, na minha opinião, porque o tempo parece que está fechado. A fisionomia dele está com olho arregalado, cara de medo, está assustado, as duas pessoas estão perseguindo, tem vários motivos, pode ser assaltado, pode ser roubado. Parece que tem um redemoinho. Por que ele está com medo? Temporal, tem gente atrás dele com medo de despencar da ponte, da cascata de Foz do Iguaçu. Eu fiquei com medo quando fui a Foz, mas foi muito legal. O medo, o tempo fechado, olhos arregalados, a perseguição, pode ser assaltado, roubado. JL projeta seu próprio medo por meio da imagem, traz sua experiência na cascata de Foz do Iguaçu, teve medo, mas também achou legal. As possibilidades são tateadas até que as reflexões se aprofundem.

Uma imagem não tem a mesma interpretação, cada um atribui-lhe um pouco de si e de seu entorno. As narrativas se multiplicam e acumulam material para uma visão que extrapola a superfície; a personagem que está com medo é imaginada em diferentes contextos que levam aos acontecimentos materializados na imagem, cede espaço para novas significações. Rodari (1982) afirma que uma personagem real ou imaginária pode ter suas aventuras pensadas pelas suas características: um homem de vidro é frágil, transparente, lavável; um homem de madeira flutua na água, não morre enforcado, queima-se com o fogo. Um homem de gelo, de papel, de manteiga, de chocolate terão narrativas bem diferentes. E um homem de tinta que grita em um quadro? É possível perceber um jogo entre o real e o imaginário, uma gangorra que busca ir até o fundo do mundo real para reformulá-lo.

Os medos pessoais são revelados por meio das narrativas: PY: Tenho medo de morrer e de morcego. MR: Não tenho medo de nada. JL: Tenho medo de perder a alma, quando a gente faz coisa errada, quando a gente peca, perde a alma. Os sujeitos entram na obra, selecionam formas para esse conteúdo, a obra não é um emaranhado de linhas. O conhecimento dos elementos visuais como as linhas, cores, formas, não levam à compreensão efetiva da imagem, precisam perceber o oculto, aquilo que não se vê, como o oculto de seus medos, pois não é possível vê-los da obra, mas dão voz e forma pelos próprios sentimentos.

Sobre o grito da personagem: MR: Ela está em um lugar, parece uma ponte perto de um rio e lá bate uma areia. PY: Perdeu o cabelo, tá com medo. MR: Medo de bicho, de cobra. PY: De desespero. MR: Tinha um monte de pessoas atrás dele; ele está no Rio de Janeiro. JL: Grita na ponte, professora. O grito recebe conotações diversas, todas possíveis, todas imaginadas. Vigotski (1999) destaca que as emoções suscitadas pela arte encontram seu lugar no exercício da imaginação. O grito para eles pode ser de medo, para chamar alguém, pelos filmes de bruxa e por um gol. São gritos imediatos.

Os participantes percebem as cores que integram a imagem, afirmam que um céu assim só existe em filme, arco-íris, tempo fechado, escuro, mas ainda com cor. PY se lembra de seu pai tirando fotos do céu em cores; destacam o fim da tarde como o momento do dia materializado na imagem. A personagem está de preto, o que segundo eles representa: pecado, morte, pesadelo, medo. A cor vermelha é descrita em conjunto com o preto: vermelho sangue, preto morte.

PY destaca que a perda do cabelo remete ao câncer, e que ficar careca é algo feio. JL intervém: Mas isso não é feio, a pessoa esteve doente e não porque é feio. Tem gente que raspa o cabelo porque quer, e outros que ficam doentes, então, não é assim. A leitura da imagem esbarra em algo para além do quadro, da personagem que grita, proporcionando reflexões sobre fatos aparentemente corriqueiros da vida. PY afirma: Isso é a vida [...] as pessoas com câncer gritam por dentro, como um grito de liberdade pra quem 
tem preconceito. Para eles o grito representa a vida, expande-se e ganha significados novos: liberdade, libertação, a vida.

A imagem representa vida e morte e não um adorno para combinar com o sofá da sala: JL: Não, ele representa coisas ruins, eu acho que o sofá é pra descansar, faz̧er várias coisas, mas a sensação do quadro dá sensação ruim. Para JL o quadro é um grito de vida e morte, representa coisas ruins e não serve para descansar, que seria a função do sofá da sala. É notória a função utilitária do sofá, entretanto, a função atribuída à obra vincula-se a questões do espírito, de representações do humano, da condição de vida e morte, às concepções mediatas. Para Schlichta (2009) a representação da imagem não se restringe à aparência da realidade, mas encarna um estado humano. A interpretação extrapola o imediato da imagem, comunicando o que as pessoas querem comunicar, seus significados e intenções pessoais, tornando-os coletivos. A imagem pressupõe interação entre as pessoas, é objeto de mediação.

Dos significados do grito: desejo de gritar, grito de medo do filme de morcego, falta de alegria, grito de medo, pesadelo, corpo com coisas ruins, predileção, expressão. O grito para MR: É ele mesmo. Para PY: O desespero. Para JL: Ele representa ele, a vida dele, a tristeza, eu acho. Representou no desenho, na pintura. As interpretações individuais e coletivas permitem a apropriação da obra oscilando entre concepções imediatas e mediatas e estabelecem diálogos que vão além da mera narrativa da imagem.

JL diz sobre a função da pintura: Acho que melhora, pois em vez. de você contar pra alguém, você desenha o seu sentimento e ele vai embora, você expressa. Para Vigotski (2004), a arte apresenta função mediadora entre o psíquico e o social, permitindo ao indivíduo o domínio de suas próprias funções psicológicas. Portanto, a arte não se restringe ao campo do imaginário, mas torna possível ações concretas.

\section{Produção artística}

A leitura da imagem, as ações propostas e as significações pessoais são referência para a produção artística de um grito pessoal envolvendo questões subjetivas e objetivas. Pela técnica de monotipia, impressão de uma única cópia, os sujeitos da pesquisa representam o grito. Iniciam por um esboço sobre papel, depois sobre uma superfície de vidro e tinta acrílica, capturam a imagem pela compressão do papel sobre o vidro, conforme Figura 2, Figura 3 e Figura 4:

Figura 2: PY. Grito perfurante radical. Monotipia sobre papel, $90 \mathrm{~g}, 45$ x $65 \mathrm{~cm}$

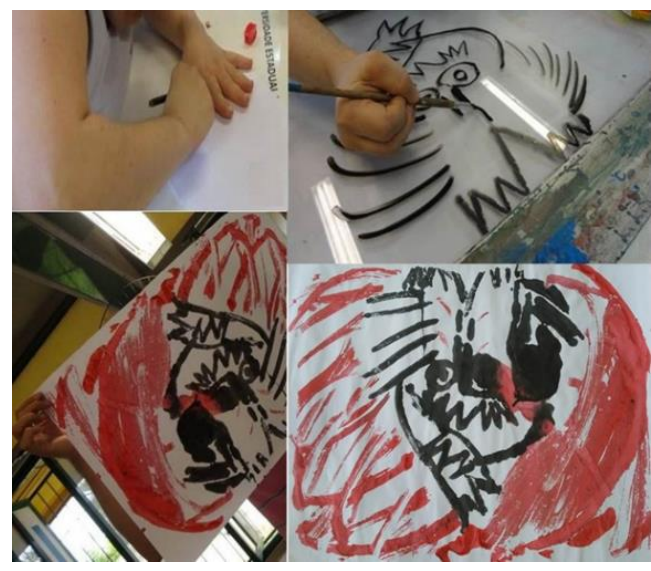

Fonte: Arquivo das autoras, 2018. 

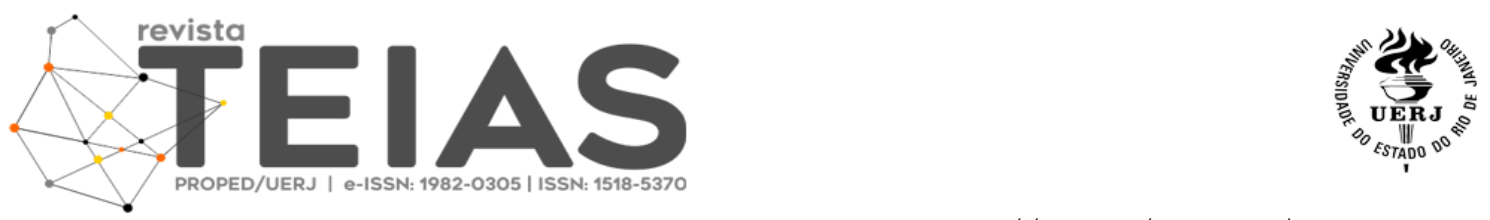

DOI: https://doi.org/10.12957/teias.2020.41757

Figura 3: MR. Medo feliz. Monotipia em papel, $90 \mathrm{~g}, 45$ x $65 \mathrm{~cm}$
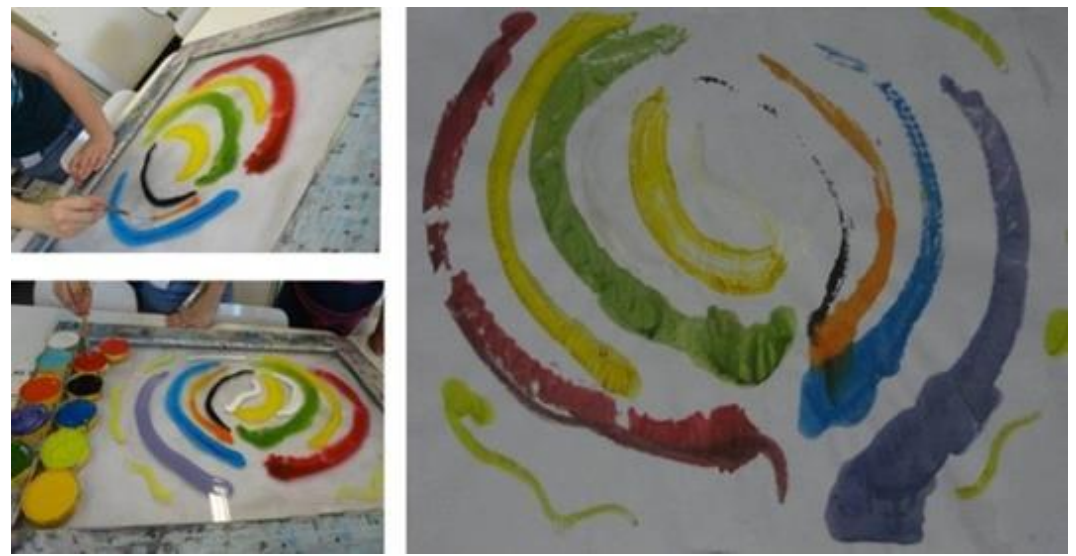

Fonte: Arquivo das autoras, 2018.

Figura 4 - JL. Coração partido. Monotipia em papel, 90g, 45 x $65 \mathrm{~cm}$
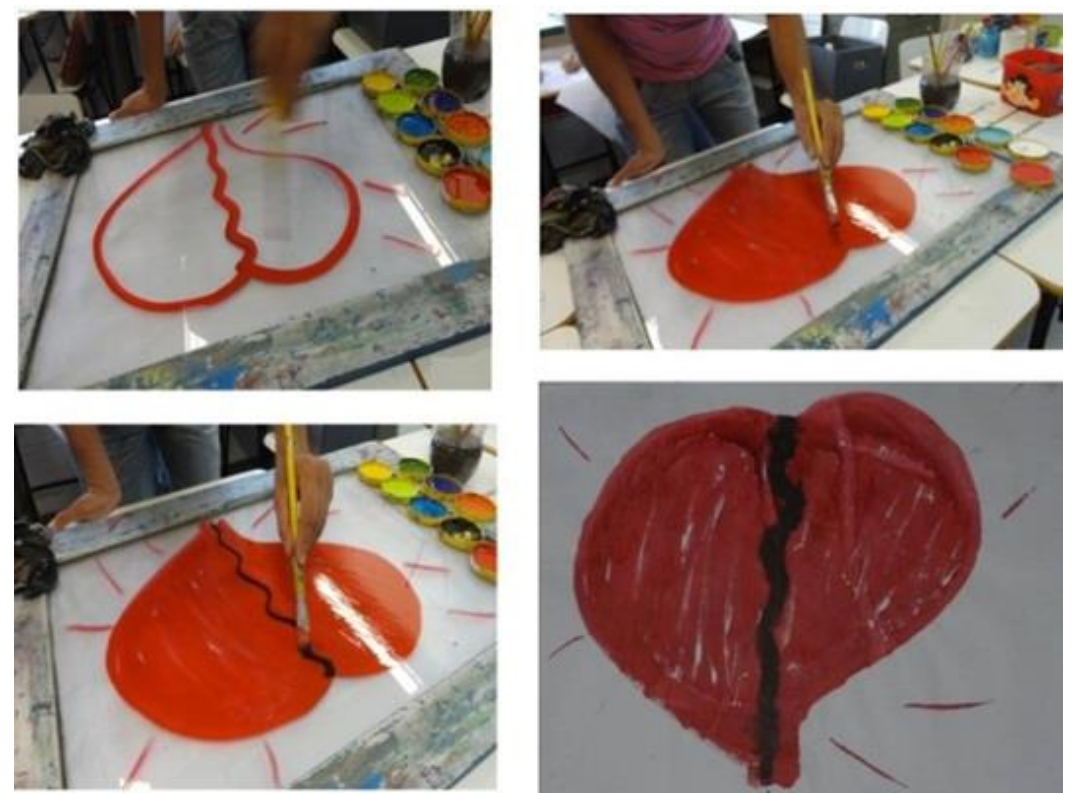

Fonte: Arquivo das autoras, 2018.

Análise da produção artística

Figura 2: A produção pictórica e a narrativa de PY remetem ao medo de morcego pela forma simbólica da imagem - utiliza a cor vermelha e o preto. O vermelho para PY é sangue, vida, paixão, o preto representa a morte. Em sua composição, vida e morte se misturam formando um amálgama pela história contada, na qual elementos subjetivos e objetivos se projetam na pintura. Faz referência a sua própria condição de menina com Síndrome de Down com sangue doce, identificando-se com a produção. Na sequência traz uma relação fílmica, volta-se ao imaginário dos vampiros e ao amor obsessivo pela figura da musa. O vocabulário é repleto de significados que ganham espaço na representação pictórica. A produção de PY vincula-se à criação de novas imagens e ações, afastando-se da referência inicial da obra de Munch, o que denota o 
comportamento criador do gênero humano que combina, reelabora e não se restringe a ações anteriores, tornando possível novos comportamentos.

Figura 3: A produção pictórica e a narrativa de MR remetem a um medo feliz, colorido: laranja, amarelo, azul, cor de rosa. Assim como PY, MR afasta-se da referência inicial da obra de Munch; seu grito, ao contrário, é feliz e colorido. Utiliza formas abstratas para representar o sentimento de felicidade junto a cores luminosas marcadas com linhas curvas em movimento circular. A existência de necessidades e anseios que põem em movimento o processo de imaginação de MR é a base da criação que reside em fatores internos e externos, segundo interesses pessoais e sociais. MR visivelmente busca o lado otimista e colorido da vida, o que pode ser observado no campo simbólico de sua produção.

Figura 4: A produção pictórica e a narrativa de JL remetem ao medo de ter o coração partido. JL é puro sentimento ao representar um coração partido; em seus dizeres, é quando o coração trinca de amor e demora para colar de novo. Em sua produção é visível o amálgama entre os fatores subjetivos e objetivos demonstrados na realidade simbólica da criação. O significado atribuído à figura extrapola a simplicidade da forma estereotipada do coração vermelho e trincado, concedendo-lhe sutilezas complexas, superando preconceitos que respondem apenas às experiências práticas e imediatas da existência. Vázquez (1977) destaca que ações generalizadas são repetidas até que novas necessidades de criação se apresentem: ocorre a repetição na forma do coração, entretanto, um novo elemento se apresenta: o significado atribuído por JL. Mediante isso, novos desafios e novas formas de ação constituem-se no imaginário aparentemente simplificado, ao dizer: Eu já me machuquei uma vež e não quero me machucar de novo. Nessa condição, o objeto de arte não é mera expressão do sujeito, é uma nova realidade que vai além dele; são provocados sentimentos pessoais e sociais que não existiam antes de sua formação; sentimentos são materializados em nova realidade que existe apenas no mundo simbólico da criação, mas que podem tornar-se realidade concreta.

\section{RESULTADOS E DISCUSSÕES}

Conforme a produção de significados das pessoas com deficiência intelectual, sujeitos dessa pesquisa, observam-se múltiplas formas de ser e estar no mundo, que envolvem aspectos individuais e sociais. Frequentemente, pessoas com deficiência intelectual nem sempre têm a oportunidade de se fazerem ouvir; para o senso comum, é como se não tivessem coisas importantes a dizer. No entanto, os resultados da pesquisa evidenciam que a fala desses sujeitos em conjunto com a produção artística por eles realizada comunicam experiências significativas e explicitam potencialidades na escolha de novas alternativas e posicionamentos perante a realidade. A ação permite disposições singulares, possíveis devido à formação de uma realidade conceitualizada, estabelecida pela relação social e psíquica que a constitui.

O Grito de Edvard Munch, imagem apresentada aos sujeitos da pesquisa, desdobra-se na produção de vários significados; a ação mediadora destaca-se, lançando pontes para além do quadro: o interno (psíquico/subjetivo) e o externo (social/objetivo). A ação mediadora, base das funções mentais complexas, permite aos participantes dominarem suas próprias operações psicológicas. A produção artística realizada mescla o subjetivo e o objetivo, ação interna e externa, advindas de experiências individuais e coletivas por eles vivenciadas e projetadas em suas criações, o que foi possível pelo trabalho vivenciado em seu aspecto criador. Desse modo, a produção de significados é elaborada nas e pelas relações humanas que apontam posicionamentos tomados a cada instante da existência. 
Mediante a proposta que envolveu o trabalho criador de produção de significados na educação de pessoas com deficiência intelectual, foi possível: atribuir novos significados à imagem da obra apresentada pela vivência do processo de criação; conceber as imagens produzidas como representações de seus próprios anseios; produzir imagens como algo concreto e real com projeção na realidade; superar gostos pessoais que legitimam diferenças sociais como naturais; estabelecer diálogos que vão além da mera narrativa do que se vê na imagem. No desenvolvimento da proposta foram consideradas, para a análise da produção, as categorias: imediato, mediação, mediato. Nesse aspecto, observa-se que a representação do imediato que corresponde ao saber inicial avançou notoriamente para a representação do mediato - a conhecimentos mais elaborados. A produção artística permitiu o pensamento abstrato por meio de escolhas conscientes, o que demonstra a passagem de concepções desarticuladas a concepções articuladas às experiências objetivas e subjetivas de cada participante. A ação subjetiva e objetiva envolveu o imaginário necessário à formação de estruturas de conceitos superiores, margeados pelo contato com a imagem e objetivado pelas escolhas compositivas, tanto das palavras, quanto dos elementos que constituíram o trabalho de criação artística dos participantes. Os significados produzidos se materializaram, o que permitiu a superação de necessidades imediatas, voltando-se às questões mediatas, pela mediação. Essa dinâmica permitiu posicionamentos criativos e criadores diante do mundo exterior, pois foram atribuídos outros fins à imagem apresentada. Diálogos estabelecidos pelos sujeitos da pesquisa explodem em significados ruidosos que não deixam calar a voz.

Por conseguinte, foi possível captar inquietações presentes no movimento expressionista e romper a ideia de arte como cópia da realidade ao serem produzidas novas imagens. A imagem apresentada, O grito, foi capaz de problematizar ações cotidianas dos sujeitos, permitindo-lhes olhar além da aparência imediata. Foi ainda capaz de solicitar a criação de novas formas pela referência objetiva em conjunto com a subjetividade de cada um: o Grito perfurante radical de PY, o Medo feliz de MR, o Coração partido de JL.

Consequentemente, os resultados da pesquisa demonstram que os sujeitos, por experimentarem a arte enquanto trabalho criador, não buscaram certezas absolutas, nem princípios sólidos, mas produziram corporificações mediante as alternativas apresentadas, ora aproveitandoas, ora descartando-as, o que configura a representação da própria existência do ser humano no mundo.

\section{CONSIDERAÇÕES FINAIS}

Eduardo Galeano (1991, p. 16) na obra O livro dos abraços, poetiza: "A uva é feita de vinho". Por meio desses escritos, constitui-se um espaço reflexivo sobre a essência que se esconde na transparência de fatos cotidianos. Ora, o significado da uva não se encontra na própria natureza, mas na cultura humana, configurada no vinho. O conhecimento não é pronto, acabado, mas alinhase em constantes futuros possíveis, reconfigurado a cada novo arranjo social e histórico. Nesse movimento, a realidade é mais complexa do que aparentemente se apresenta, o que possibilita a constituição de seres históricos e sociais que, ao ultrapassarem explicações cotidianas, transformam uva em vinho.

Do mesmo modo, ao problematizar-se sobre a constituição da produção de significados na educação de pessoas com deficiência intelectual, cogitando a autoprodução humana e a superação de si mesmo, conclui-se que os resultados produzidos pelos sujeitos da pesquisa comunicaram diversas visões de mundo, significados que se estabeleceram no processo do trabalho e deixaram à mostra seu aspecto criador, ao transformarem traços coloridos na representação das próprias experiências individuais e coletivas. A arte, reafirma-se, enquanto trabalho criador produz 
corporificações mediante alternativas apresentadas, ora aproveitando-as, ora descartando-as, o que configura a representação da própria existência do ser humano no mundo. A produção artística permite aos sujeitos da pesquisa o andarilhar por caminhos cotidianos que se desdobram em inúmeras alternativas e intencionalidades, lugares em que a arte é forte aliada da constituição humana, pela qual novos elementos se combinam e projetam novas realidades. Nessa relação, o conhecimento artístico não se configura como privilégio de poucos. Mas a arte, concebida como trabalho criador, projeta-se humanamente e apresenta-se não como fim, mas como meio.

\section{REFERÊNCIAS}

BRASIL. Constituição Federal de 1988. Promulgada em 5 de outubro de 1988. Disponível em: http://www.planalto.gov.br/ccivil 03/constituicao/constituição.htm. Acesso em: 1 abr. 2019.

BRASIL. Lei de Diretrizes e Bases da Educação: Lei no. 9394/96, de 20 de dezembro de 1996.

BRASIL. Política Nacional de Educação Especial na Perspectiva da Educação Inclusiva. Documento elaborado pelo Grupo de Trabalho nomeado pela Portaria n ${ }^{\circ} .555 / 2007$, prorrogada pela Portaria n'. 948/2007, entregue ao Ministro da Educação em 07 de janeiro de 2008. Disponível em: http://portal.mec.gov.br/arquivos/pdf/politicaeducespecial.pdf. Acesso em: 1 abr. 2019.

BRASIL. Estatuto da Pessoa com Deficiência: Lei no . 13.146. Promulgada em 6 de julho de 2015. Institui a Lei Brasileira de Inclusão da Pessoa com Deficiência (Estatuto da Pessoa com Deficiência). Disponível em: http://www.punf.uff.br/inclusao/images/leis/lei 13146.pdf. Acesso em: 1 abr. 2019.

CANCLINI, Nestor García. A socialização da arte: teoria e prática na América Latina. São Paulo: Cultrix, 1980.

CARVALHO, Saulo Rodrigues de; MARTINS, Lígia Márcia. A sociedade capitalista e a inclusão/exclusão. In: FACCI, Marilda Gonçalves Dias; MEIRA, Marisa Eugênia Melillo; TULESKI, Silvana Calvo (orgs.). A exclusão dos "incluídos": uma crítica da psicologia da educação à patologização e medicalização dos processos educativos. 2. ed. Maringá: Eduem, 2012, p. 19-32.

EVANS, Peter. Algumas implicações da obra de Vygotsky na educação especial. In: DANIELS, Harry (org.). Vygotsky em foco: pressupostos e desdobramentos. 2. ed. Campinas, São Paulo: Papirus, 1995, p. 69-89.

GALEANO, Eduardo. O livro dos abraços. Porto alegre: L\&PM, 1991.

GOMBRICH, Ernst Hans Josef. A história da arte. 16. ed. Tradução Álvaro Cabral. Rio de Janeiro: LTC, 2012.

KLEIN, Lígia Regina; SILVA, Graziela Rosa Lucchesi da; MATA, Vilson Aparecido da. Alienação e exclusão: refletindo o processo de "inclusão" na educação de jovens e adultos. In: FACCI, Marilda Gonçalves Dias; MEIRA, Marisa Eugênia Melillo; TULESKI, Silvana Calvo (orgs.). A exclusão dos "incluidos": uma crítica da psicologia da educação à patologização e medicalização dos processos educativos. 2. ed. Maringá: Eduem, 2012, p. 211-232.

FOUCAULT, Michel. História da loucura: na idade clássica. 11. ed. Tradução José Teixeira Coelho Neto. São Paulo: Perspectiva, 2017.

KOSÍK, Karel. Dialética do concreto. 3. ed. Rio de Janeiro: Paz e Terra, 1976.

LESSA, Sérgio. Mundo dos homens: trabalho e ser social. São Paulo: Instituto Lukács, 2012.

LUKÁCS, György. Para uma ontologia do ser social II. 1. ed. São Paulo: Boitempo, 2013. 
MARTINS, Lígia Márcia. As aparências enganam: divergências entre o materialismo histórico dialético e as abordagens qualitativas de pesquisa. Trabalho apresentado na 29a. Reunião Anual da ANPED, 2006. Recuperado em 20 de setembro de 2011, de http://www.anped.org.br/reunioes/29ra/trabalhos/trabalho/GT17-2042--Int.pdf. Disponível em: $\quad$ https://social.stoa.usp.br/articles/0016/4005/As aparA ncias enganam _divergencias_entre_o_mhd_e_as_abordagens_qualitativas.pdf. Acesso em: 1 abr. 2019.

MARX, Karl; ENGELS, Friedrich. Sobre literatura e arte. 3. ed. São Paulo: Global, 1986.

MÉSZÁROS, István. A educação para além do capital. Revista Theomai, n. 015, p. 107-130, primer semestre, 2007. Red Internacional de Investigadores Theomai sobre Sociedad, Naturaleza y Desarrollo. Quilmes, Argentina.

MORI, Nerli Nonato Ribeiro. Metodologia de pesquisa. Maringá: Eduem, 2011.

ORGANIZAÇÃO DAS NAÇÕES UNIDAS. Declaração Universal dos Direitos Humanos (DUDH). Documento elaborado por representantes de diferentes origens jurídicas e culturais de todas as regiões do mundo, proclamada pela Assembleia Geral das Nações Unidas em Paris, em 10 de dezembro de 1948.

ORGANIZAÇÃO DAS NAÇÕES UNIDAS PARA A EDUCAÇÃO, A CIÊNCIA E A CULTURA (UNESCO). Declaração de Salamanca. Sobre Princípios, Políticas e Práticas na Área das Necessidades Educativas Especiais. Disponível em: http://portal.mec.gov.br/seesp/arquivos/pdf/salamanca.pdf . Acesso em: 1 abr. 2019.

READ, Herbert. História da pintura moderna. Rio de Janeiro: Zahar, 1980.

RODARI, Gianni. Gramática da fantasia. São Paulo: Summus, 1982.

SAVIANI, Dermeval. Educação: do senso comum à consciência filosófica. 5. ed. São Paulo: Cortez: Autores Associados, 1985.

SCHLICHTA, Consuelo. Arte e educação: haverá um lugar para a Arte no Ensino Médio? Curitiba: Aymará, 2009.

SHIMAZAKI, Elsa Midori; MORI, Nerli Nonato Ribeiro. Atendimento educacional especializado à pessoa com deficiência intelectual. In: SHIMAZAKI, Elsa Midori; PACHECO, Edilson Roberto. Deficiência e inclusão escolar. Maringá: Eduem, 2012, p. 55-67.

VÁZQUEZ, Adolfo Sánchez. Filosofia da práxis. 2. ed. Rio de Janeiro: Paz e Terra, 1977.

VIGOTSKI, Lev Semenovich. A formação social da mente: o desenvolvimento dos processos psicológicos superiores. Tradução José Cipolla Neto, Luís Silveira Menna Barreto, Solange Castro Afeche. 7. ed. São Paulo: Martins Fontes, 2007.

VIGOTSKI, Lev Semenovich. Imaginação e criação na infância: ensaio psicológico. Apresentação e comentários Ana Luiza Smolka; tradução Zoia Prestes. São Paulo: Ática, 2009.

VIGOTSKI, Lev Semenovich. Psicologia da arte. São Paulo: Martins Fontes, 1999.

VIGOTSKI, Lev Semenovich. Psicologia pedagógica. Tradução do russo e introdução de Paulo Bezerra. 2. ed. São Paulo: Martins Fontes, 2004. 


\section{Informações das autoras}

Tania Regina Rossetto

Instituto Federal do Paraná (IFPR) Campus Palmas

E-mail: tania.rossetto@ifpr.edu.br

ORCID: https://orcid.org/0000-0003-1988-0581

Link Lattes: http://lattes.cnpq.br/4072169518562105

Nerli Nonato Ribeiro Mori

Universidade Estadual de Maringá (UEM)

E-mail:nnrmori@uem.br

ORCID: https://orcid.org/0000-0002-6798-5225

Link Lattes: http://lattes.cnpq.br/0771300635766380 